\title{
Heterozygosity for the Common LCHAD Mutation (1528G > C) Is Not a Major Cause of HELLP Syndrome and the Prevalence of the Mutation in the Dutch Population Is Low
}

\author{
MARGARETHE E.J. DEN BOER, LODEWIJK IJLST, FRITS A. WIJBURG, WENDY OOSTHEIM, \\ MICHIEL A. VAN WERKHOVEN, MARIELLE G. VAN PAMPUS, HUGO S.A. HEYMANS, AND \\ RONALD J.A. WANDERS \\ Departments of Pediatrics [M.E.J.D.B., F.A.W., H.S.A.H., R.J.A.W.], Clinical Chemistry [L.I., W.O., \\ M.A.V.W., R.J.A.W.], and Obstetrics [M.G.V.P.], Academic Medical Center, University of Amsterdam, \\ NL-1100 DD Amsterdam, The Netherlands
}

\begin{abstract}
Long-chain 3-hydroxyacyl-CoA dehydrogenase (LCHAD) deficiency is an autosomal recessive disorder of mitochondrial fatty acid oxidation. Apart from life-threatening metabolic derangement with hypoketotic hypoglycemia, patients often show liver disease, cardiomyopathy, and neuropathy. A common mutation $(1528 \mathrm{G}>\mathrm{C})$ in the gene coding for the $\alpha$-subunit of the mitochondrial trifunctional protein harboring LCHAD activity is found in $87 \%$ of the alleles of patients. LCHAD is considered a rare disorder with only 63 patients reported in the literature. Whether this is due to a truly low prevalence of the disorder or because many patients remain unrecognized as a result of aspecific symptomatology is not clear. A remarkable association between LCHAD deficiency and the hemolysis, elevated liver enzymes, and low platelets (HELLP) syndrome, which is a severe complication of pregnancy, has been reported. Because of this, we studied the frequency of the common LCHAD mutation in the Dutch population by analyzing 2047 Guthrie cards and 113 women who had suffered from HELLP syndrome. To be able to
\end{abstract}

\section{ABSTRACT}

perform this large-scale study in dried bloodspots, we developed a new sensitive PCR-restriction fragment length polymorphism method. The carrier frequency for the common LCHAD mutation in the Dutch population was found to be low (1:680), consistent with the observed low incidence of the disorder. In the group of women with a history of HELLP syndrome, the prevalence of the common LCHAD mutation was also low (1:113). We conclude that LCHAD deficiency is, indeed, a rare disorder and that heterozygosity for the common mutation is not a major cause of the HELLP syndrome. (Pediatr Res 48: 151-154, 2000)
Abbreviations
AFLP, acute fatty liver of pregnancy
HELLP, hemolysis, elevated liver enzymes, and low platelets
LCHAD, long-chain 3-hydroxyacyl-CoA dehydrogenase
MCAD, medium-chain acyl-CoA dehydrogenase
PCR-RFLP, PCR-restriction fragment length polymorphism

LCHAD deficiency is one of the 13 inborn errors of mitochondrial fatty acid oxidation currently known. In patients with LCHAD deficiency, the oxidation of long-chain fatty acids is impaired due to mutations in the gene coding from the $\alpha$-subunit of the mitochondrial trifunctional protein. The latter protein is an octamer of four $\alpha$ - and four $\beta$-subunits. The $\alpha$-subunit harbors the enoyl-CoA hydratase and 3-hydroxyacyl-CoA dehydrogenase activities, whereas the $\beta$-subunit carries the thiolase activity.

LCHAD deficiency is an autosomal recessive disorder. Patients usually present in infancy with recurrent attacks of hypoketotic hypoglycemia provoked by prolonged fasting, often during a

Received January 21, 1999; accepted June 17, 1999.

Correspondence: R.J.A. Wanders, Ph.D., Department of Pediatrics (Room F0-226), Academic Medical Center, University of Amsterdam, P.O. Box 22660, NL-1100 DD Amsterdam, The Netherlands. minor intercurrent illness such as gastroenteritis (1). In addition, cardiomyopathy $(1,2)$ and hepatomegaly with cholestatic jaundice, which can sometimes progress to fulminant liver failure, are regularly observed $(2,3)$. Peripheral neuropathy and pigmentary retinopathy can occur during the course of the disease (2-5). LCHAD deficiency can also present as sudden infant death even in the neonatal period $(2,6)$.

The diagnosis of LCHAD deficiency is suggested by demonstrating the presence of large amounts of 3-hydroxy-dicarboxylic acids in the urine and by assessment of the acylcarnitine profile in plasma by tandem mass spectrometry (7). Definitive diagnosis requires enzymatic studies, which may be performed in liver, muscle, lymphocytes, and fibroblasts (8-10).

The gene for the $\alpha$-subunit of the mitochondrial trifunctional protein carrying LCHAD activity is located on chromosome 2, 
and the genomic structure of the gene has been clarified (11). Most remarkable is the occurrence of a common point mutation $(1528 \mathrm{G}>\mathrm{C})$ in LCHAD deficiency $(12-14)$, accounting for $87 \%$ of the affected alleles in 70 patients investigated (12). This common mutation makes diagnosis at the molecular level feasible (12).

Remarkably, severe complications during pregnancy, including HELLP syndrome and AFLP, have been reported in mothers who are heterozygous carriers of the LCHAD mutation (14-16). HELLP syndrome is a serious complication of pregnancy occurring in approximately 4 to $20 \%$ of women with severe preeclampsia (17). AFLP is another complication of pregnancy characterized by severe progressive liver disease in approximately $50 \%$ of cases complicated by preeclampsia and is sometimes observed in combination with HELLP syndrome $(15,18)$. HELLP syndrome carries a high risk for serious morbidity and even mortality for the affected mother and her child (17). Although several mechanisms have been proposed, the exact pathophysiologic mechanism(s) causing HELLP syndrome and AFLP still remains unclear $(17,18)$. The similarities between the liver disease seen in LCHAD deficiency and in HELLP syndrome as well as in AFLP, with microvesicular or macrovesicular steatosis, in combination with the reported high incidence of these gestational complications in mothers heterozygous for the LCHAD mutation suggest a causal relationship between a compromised long-chain fatty acid oxidation and HELLP and AFLP $(14-16,19,20)$. However, it is uncertain whether the risk of these gestational complications is limited to those pregnancies in which the fetus is homozygous for the LCHAD mutation. Nevertheless, in some centers, mutation screening is offered to all mothers who suffered from HELLP syndrome or AFLP to allow presymptomatic diagnosis of LCHAD-deficient newborns.

We decided to study the prevalence of the common LCHAD mutation $(1528 \mathrm{G}>\mathrm{C})$ in women who suffered from HELLP syndrome during pregnancy and to compare this prevalence with the frequency of the $1528 \mathrm{G}>\mathrm{C}$ mutation in the Dutch population to determine whether screening of mothers or their offspring for the LCHAD mutation is justified.

A PCR-RFLP method using a PstI restriction site has previously been described, making detection of heterozygous individuals possible (12). However, an important drawback of this method is that the sensitivity is not high enough when samples with a relatively low DNA concentration are used, because of the large amplified fragment ( $640 \mathrm{bp}$ ). To be able to perform large-scale sensitive screening for the common LCHAD mutation in dried bloodspots, we developed a novel improved PCR-RFLP method and applied the method to establish the frequency of the $1528 \mathrm{G}>\mathrm{C}$ mutation in bloodspots from control persons and women with a history of HELLP syndrome.

\section{METHODS}

DNA extraction from bloodspots. DNA was extracted from bloodspots by using Chelex (BioRad) essentially as described before (21) with some modifications. To this end, a sample (3-mm diameter) was taken from a dried bloodspot and washed with $1 \mathrm{~mL}$ of sterile water for $30 \mathrm{~min}$ at $50^{\circ} \mathrm{C}$ in a $1.5-\mathrm{mL}$ Eppendorf tube. Thereafter, $200 \mu \mathrm{L}$ of Chelex $(50 \mathrm{~g} / \mathrm{L}, \mathrm{pH}$ 10.5) was added and incubated at $56^{\circ} \mathrm{C}$ for 30 min. Subsequently, the samples were mixed for $10 \mathrm{~s}$ and centrifuged $(3$ $\min , 10,000 \times g$ ), followed by an 8 -min incubation in a boiling water bath. After cooling to room temperature, the samples were mixed for $10 \mathrm{~s}$ and centrifuged $(3 \mathrm{~min}, 10,000 \times g)$. Ten microliters of sample was used in a $25-\mu \mathrm{L}$ PCR reaction.

PCR-RFLP for the common LCHAD $(1528 G>C)$ mutation. To increase sensitivity of the used PCR-RFLP method, we aimed to amplify a fragment smaller than the fragment of $640 \mathrm{bp}$ used before (12). To prevent interference of the pseudogene as identified by Zang and Baldwin (11), a new primer had to be selected in intron 15 . Because the sequence of this intron has not been published, we sequenced intron $15 \mathrm{com}$ pletely (data not shown). Based on the obtained sequence, different primer sets were selected. Only with the primer set used here (see below), a specific PCR fragment with high yield was obtained. The product contains a predicted PstI site that can serve as a convenient internal control.

Exon 15 and part of intron 15 were amplified in a $25-\mu \mathrm{L}$ PCR reaction containing $10 \mathrm{mM}$ Tris- $\mathrm{HCl}\left(\mathrm{pH} 8.4\right.$ at $\left.25^{\circ} \mathrm{C}\right)$, $1.2 \mathrm{mM} \mathrm{MgCl}_{2}, 50 \mathrm{mM} \mathrm{KCl}, 0.1 \mathrm{mg} / \mathrm{mL}$ BSA, dNTP $(0.2 \mathrm{mM}$ each), 2.5 U Taq polymerase (Promega), and the following primer set (12.5 pmol each): sense primer 5'-CCC TTG CCA GGT GAT TGG C-3', antisense primer 5'-ACA AGC CTG GAG GTA AAA GG-3'. DNA amplification was performed in a PTC-100 thermocycler from M.J. Research, Inc., programmed as follows: $120 \mathrm{~s}$ at $96^{\circ} \mathrm{C}$ initial to cycling, five cycles of $30 \mathrm{~s}$ at $96^{\circ} \mathrm{C}, 30 \mathrm{~s}$ at $55^{\circ} \mathrm{C}$, and $30 \mathrm{~s}$ at $72^{\circ} \mathrm{C}$ followed by 25 cycles of $30 \mathrm{~s}$ at $94^{\circ} \mathrm{C}, 30 \mathrm{~s}$ at $55^{\circ} \mathrm{C}$, and $30 \mathrm{~s}$ at $72^{\circ} \mathrm{C}$ and the end of cycling $10 \mathrm{~min}$ at $72^{\circ} \mathrm{C}$. The amplified fragment (224 bp) was directly digested after addition of $2.5 \mu \mathrm{L}$ of buffer $\mathrm{M}$ and $5 \mathrm{U}$ of Pst (Boehringer Mannheim).

The restriction fragments were analyzed on a $2 \%(\mathrm{wt} / \mathrm{vol})$ agarose gel with ethidium bromide staining. To validate this method, we performed PCR-RFLP in dried bloodspots from a control subject, a homozygous $1528 \mathrm{G}>\mathrm{C}$ patient, and both parents.

Population screening for the common LCHAD mutation. In the Netherlands, approximately $99 \%$ of all newborns ( $\pm 200,000$ live births yearly) are tested for phenylketonuria and congenital hypothyroidism in a nationwide screening program by means of Guthrie cards. For this study, 2047 Guthrie cards were anonymously obtained from the screening laboratories representing the 12 Dutch provinces and the two largest cities (Amsterdam and Rotterdam) after approval by the Dutch health authorities. The total number of cards selected from each of the 14 screening areas and used in our population screening was proportional to the number of live births in each of these regions, which guarantees a demographic representation of the Dutch population.

Confidence intervals (CI) were calculated using the method for estimating the population carrier rate when some carriers are not detected as described by Parker and Philips (22), accounting for the $87 \%$ allele frequency of the common $1528 \mathrm{G}>\mathrm{C}$ mutation in LCHAD-deficient patients. 
Prevalence of the common LCHAD mutation in HELLP syndrome. HELLP syndrome was defined as hemolytic anemia $(\mathrm{LDH}>600 \mathrm{U} / \mathrm{L})$, elevated liver enzymes $($ ASAT $>70 \mathrm{U} / \mathrm{L})$, and thrombocytopenia (thrombocytes $<100 \times 10^{9} / \mathrm{L}$ ) during pregnancy (23).

A total of 113 women who had suffered from HELLP syndrome during at least one of their pregnancies were included in this study. Inclusion was regardless of the outcome of the affected pregnancy. Bloodspots on Guthrie cards were collected from all 113 women. This study was approved by the Institutional Medical Ethical Committee.

\section{RESULTS}

To be able to do the studies described in this article, we had to set up a new sensitive method allowing unequivocal identification of the $1528 \mathrm{G}>\mathrm{C}$ mutation in bloodspots. The result of this new procedure is shown in Figure 1.

After restriction of the amplified fragment from a control bloodspot, the predicted restriction fragment of $175 \mathrm{bp}$ (and 49 bp) was obtained. In a patient known to be homozygous for the $1528 \mathrm{G}>\mathrm{C}$ mutation, a smaller restriction fragment of 117 (58 and $49 \mathrm{bp}$ ) was found, indicating that PstI has cut at both the control site and at the position of the mutation. Both fragments of 175 and 117 bp were visible using material from both
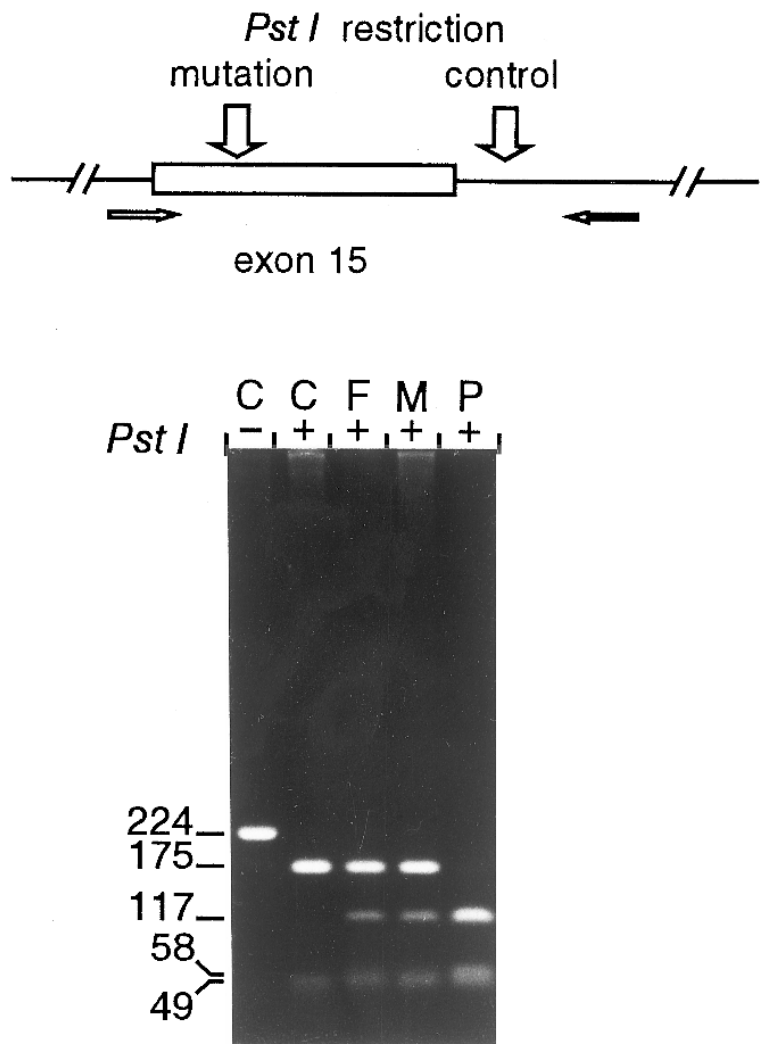

Figure 1. PCR-RFLP analysis of the $1528 \mathrm{G}>\mathrm{C}$ mutation. Upper part, Schematic representation of a part of the gene. The primers are indicated by horizontal arrows; positions of the PstI restriction sites are indicated by vertical arrows. Lower part, Ethidium bromide-stained agarose gel showing PCR-RFLP analysis using DNA extracted from dried bloodspots of a control subject $(C)$, a LCHAD-deficient patient $(P)$, and the father $(F)$ and the mother $(M)$ of the patient. PCR products were either directly loaded $(-)$ or digested with PstI (+) before electrophoresis. parents, which is compatible with heterozygosity (Fig. 1, lower panel). The PCR product contains a predicted PstI site that can serve as a convenient internal control (Fig. 1, upper panel).

Screening for the common LCHAD mutation $(1528 \mathrm{G}>\mathrm{C})$ by use of the new PCR-RFLP method in the 2047 Guthrie cards obtained form the neonatal screening centers detected three carriers for this mutation. No homozygous-deficient samples were found. The prevalence of the common $(1528 \mathrm{G}>\mathrm{C})$ LCHAD mutation in the Dutch population is thus estimated to be $1: 680(95 \%$ CI of $1: 325$ to $1: 1400)$.

Among the 113 women who suffered from HELLP syndrome during at least one of their pregnancies, one carrier for the $1528 \mathrm{G}>\mathrm{C}$ mutation was identified (prevalence $1: 113,95 \%$ CI of $1: 18$ to $1: 560)$.

The prevalences of the common LCHAD mutation among the general Dutch population and among women who suffered from the HELLP syndrome are not statistically different (2tailed Fisher exact test, $p$ value 0.19).

\section{DISCUSSION}

Inborn errors of mitochondria fatty acid oxidation are often diagnosed with considerable delay because of the aspecific symptomatology. For instance, $20 \%$ of the MCAD-deficient patients were diagnosed after death, and, in $25 \%$, a sibling had suddenly died without a proper diagnosis (24) but probably due to MCAD deficiency. Although MCAD deficiency is a relatively common disorder among Caucasians with a prevalence of the common mutation (985G $>A$ ) ranging from 1:333 in Italy (25) to as high as 1:55 in the Netherlands (26), LCHAD deficiency seems to be a much rarer disorder. Whereas in the Netherlands every year approximately 14 patients are diagnosed with MCAD deficiency in accordance with the carrier frequency for the common mutation, only six patients with LCHAD deficiency have been identified in the last $10 \mathrm{y}$. However, it may well be that the diagnosis of LCHAD deficiency is even more frequently missed than MCAD deficiency because it is not generally known that cholestatic jaundice and cardiomyopathy can be the presenting signs and symptoms in fatty acid oxidation disorders such as LCHAD deficiency. For this reason, population screening for the common LCHAD mutation $(1528 \mathrm{G}>\mathrm{C}$, allele frequency $87 \%$ ) was performed.

Because the previously described PCR-RFLP method (12) has a low sensitivity for the heterozygous detection in samples with relatively low concentration of DNA such as bloodspots, a new and more sensitive method was developed. Recently Ding et al. (27) described a sensitive nested PCR-RFLP method. The origin of the PCR product was then confirmed by a gene (and not a pseudogene) specific restriction site for $P v u \mathrm{I}$. This 2-step amplification method works well but is too laborious for processing large numbers of samples. The method described here is a simple 1-step PCR-RFLP method that only amplifies the coding gene. Furthermore, the method uses a second PstI site as internal control for the restriction, preventing false-negative results. Therefore, this PCR-RFLP method is superior to the previously described methods and allows heterozygous detection in dried bloodspots, making our carrier frequency studies possible. 
The observed prevalence of the carrier frequency for the common LCHAD mutation of 1:680 (CI 1:325-1:1400) in the Dutch population is indeed much lower than that of the MCAD mutation (1:55) and, with approximately 200,000 live births yearly, corresponds well with the low number of patients diagnosed in the last decade. It is, therefore, unlikely that many patients are missed because of an aspecific presentation.

To study the relation between HELLP syndrome and AFLP on the one hand and LCHAD deficiency on the other hand, we compared the observed prevalence with the frequency of the $1528 \mathrm{G}>\mathrm{C}$ mutation in a group of women who had suffered from HELLP syndrome.

It is important to keep in mind that our study only allows conclusions related to HELLP syndrome. Although AFLP is regarded as part of the spectrum of the group of gestational disorders that includes HELLP syndrome, further studies are necessary to see whether heterozygosity for the common LCHAD mutation is an important risk factor for the development of AFLP.

Our results clearly show that almost none of the women with a history of HELLP syndrome carries the $1528 \mathrm{G}>\mathrm{C}$ mutation. These results are important especially because it has been suggested that mutation screening should be performed in women suffering from the HELLP syndrome (16). The results of our study provide no justification for this.

\section{REFERENCES}

1. Roe CR, Coates PM 1995 Mitochondrial fatty acid oxidation disorders. In: Scrive CR, Beaudet AL, Sly WS, Valle D (eds) The Metabolic and Molecular Bases of Inherited Disease, 7th Ed. McGraw-Hill, New York, pp 1510-1515

2. Tynii T, Palotie A, Viinikka L, Valanne L, Salos MK, von Dobeln U, Jackson S, Wanders RJA, Venizelos N, Pihko H 1997 Long-chain 3-hydroxyacyl coenzyme A dehydrogenase deficiency with the G1528C mutation: clinical presentation of 13 patients. J Pediatr 130:67-76

3. Pons R, Roig M, Riudor E, Ribes A, Briones P, Ortigosa L, Baldellou A, GilGibernau J, Olesti M, Navarro C, Wanders RJA 1996 The clinical spectrum of long-chain 3-hydroxyacyl-CoA dehydrogenase deficiency. Pediatr Neurol 14:236243

4. Bertini E, Dionici-Vici C, Garavaglia B, Burlina AB, Sabatelli M, Rimoldi M, Bartuli A, Sabetta G, DiDonato S 1992 Peripheral sensory-motor polyneuropathy, pigmentary retinopathy, and fatal cardiomyopathy in long-chain 3-hydroxyacyl CoA dehydrogenase deficiency. Eur J Pediatr 151:121-126

5. Dionisi Vici C, Burlina AB, Bertini E, Backmann C, Mazziotta MRM, Sabatelli G, Hale DE 1991 Progressive neuropathy and recurrent myoglobinuria in a child with long-chain 3-hydroxyacyl coenzyme A dehydrogenase deficiency. J Pediatr 118:744746

6. Duran M, Wanders RJA, de Jager JP, Dorland L, Bruinvis L, Ketting D, IJlst L, van Sprang FJ 1990 3-Hydroxydicarboxylic aciduria due to long-chain 3-hydroxyacylcoenzyme A dehydrogenase deficiency associated with sudden neonatal death: protective effect of medium-chain triglyceride treatment. Eur J Pediatr 150:190-195
7. Millington DS, Terada N, Chace DH, Chen YT, Ding JH, Kodo N, Roe CR 1992 The role of tandem mass spectrometry in the diagnosis of fatty acid oxidation disorders. Prog Clin Biol Res 375:339-354

8. IJlst L, Mandel H, Oostheim W, Ruiter JP, Gutman A, Wanders RJA 1998 Molecular basis of hepatic carnitine palmitoyltransferase I deficiency. J Clin Invest 102:527-531

9. Wanders RJA, IJlst L, Poggi I, Bonnefont JP, Munnich A, Brivet M, Rabier M, Saudubray JM 1992 Human trifunctional protein deficiency: a new disorder of mitochondrial fatty acid $\beta$-oxidation. Biochem Biophys Res Commun 188:11391145

10. Wanders RJA, IJlst L, van Gennip AH, Jakobs C, de Jager JP, Dorland L, van Sprang FJ, Duran M 1990 Long-chain 3-hydroxyacyl-CoA dehydrogenase deficiency. Identification of a new inborn error of mitochondrial fatty acid $\beta$-oxidation. J Inherit Metab Dis 13:311-314

11. Zhang QX, Baldwin GS 1994 Structures of the human cDNA and gene encoding the $78 \mathrm{kD}$ gastrin-binding protein and of a related pseudogene. Biochim Biophys Acta 1291:567-575

12. IJlst L, Ruiter JPN, Hoovers JMN, Jakobs ME, Wanders RJA 1996 Common missense mutation G1528C in long-chain 3-hydroxyacyl-CoA dehydrogenase deficiency. J Clin Invest 98:1028-1033

13. IJlst L, Wanders RJA, Ushikubo S, Kamijo T, Hashimoto T 1994 Molecular basis of long-chain 3-hydroxyacyl-CoA dehydrogenase deficiency: identification of the major disease-causing mutation in the $\alpha$-subunit of the mitochondrial trifunctional protein. Biochim Biophys Acta 1215:347-350

14. Sims HF, Brackett JC, Powell CK, Treem WR, Hale DE, Bennett MJ, Gibson B, Shapiro S, Strauss AW 1995 The molecular basis of pediatric long-chain 3-hydroxyacyl-CoA dehydrogenase deficiency associated with maternal acute fatty liver of pregnancy. Proc Natl Acad Sci USA 92:841-845

15. Treem WR, Shoup ME, Hale DE, Bennett MJ, Rinaldo P, Millington DS, Stanley CA, Riely CA, Hyams JS 1996 Acute fatty liver of pregnancy, hemolysis, elevated liver enzymes, and low platelets syndrome, and long-chain 3-hydroxyacyl-coenzyme A dehydrogenase deficiency. Am J Gastroenterol 91:2293-2300

16. Wilcken B, Leung K, Hammond J, Kamath R, Leonard JV 1993 Pregnancy and fetal long-chain 3-hydroxyacyl-CoA dehydrogenase deficiency. Lancet 341:407-408

17. Geary M 1997 The HELLP syndrome. Br J Obstet Gynaecol 104:887-891

18. Rolfes DB, Ishak KG 1985 Acute fatty liver of pregnancy: a clinicopathologic study of 35 cases. Hepatology 5:1149-1158

19. Treem WR, Rinaldo P, Hale DE, Stanley CA, Millington DS, Hyams JS, Jackson S, Turnbull DM 1994 Acute fatty liver of pregnancy and long-chain 3-hydroxyacyl-CoA dehydrogenase deficiency. Hepatology 19:339-345

20. Schoeman MN, Batey RG, Wilcken B 1991 Recurrent acute fatty liver of pregnancy associated with fatty-acid oxidation defect in the offspring. Gastroenterology 100:544-548

21. Walsh PS, Metzger DA, Higuchi R 1991 Chelex 100 as a medium for simple extraction of DNA for PCR-based typing from forensic material. Biotechniques 10:506-513

22. Parker RA, Philips III JA 1994 Population screening for carrier status: effects of test limitations on precision of carrier prevalence rates. Am J Med Genet 49:317-322

23. Sibai BM 1990 The HELLP syndrome (hemolysis, elevated liver enzymes, and low platelets): much ado about nothing? Am J Obstet Gynecol 162:311-316

24. Iafolla AK, Thompson RJ, Roe CR 1994 Medium-chain acyl-coenzyme A dehydrogenase deficiency: clinical course in 120 affected children. J Pediatr 124:409-415

25. Gregersen N, Winter V, Curtis D, Deufel T, Mack M, Hendrickx J, Willems PJ, Ponzone A, Parella T, Ponzone R, Ding JH, Zhang W, Chen YT, Kahler S, Kolvraa S, Schneidermann AK, Andresen BS, Bross P, Bolund L 1993 Medium-chain acyl-CoA dehydrogenase (MCAD) deficiency: the prevalent mutation G985 (K304E) is subject to a strong founder effect from northwestern Europe. Hum Hered 43:342350

26. de Vries HG, Niezen-Koning K, Kliphuis JW, Smit GPA, Schepper H, ten Kate LP 1996 Prevalence of carriers of the most common medium-chain acyl-CoA dehydrogenase (MCAD) deficiency mutation (G985A) in The Netherlands. Hum Genet $98: 1-2$

27. Ding J, Yang B, Nada MA, Roe CR 1996 Improved detection of the G1528C mutation in LCHAD deficiency. Biochem Mol Med 58:46-51 